\title{
Building a dual identity as an immigrant in the UK: Eritreans' search for freedom and a sense of balance
}

Safa Ali, Jane Ogden and Michèle D. Birtel

School of Psychology, University of Surrey, Guildford, UK

\section{ABSTRACT}

This study explored the experiences of newly arrived and settled Eritrean immigrants currently in the UK. Semi-structured interviews were carried out with ten newly arrived (<one year) and ten settled (>seven years) participants, recruited through an Eritrean café and using snowball sampling. Thematic analysis identified three themes: (1) Wanting freedom, expectations of the UK and the desire for safety, (2) Integration and becoming part of the British community, (3) Personal development, which involved growth and aspirations. Transcending these themes was the notion of balance, and the co-existence of past and present. It is argued that Eritreans in the UK wish to become part of British community whilst at the same time remembering and celebrating their Eritrean culture. This is explained within the context of a dual identity and it is argued that rather than being a hindrance, a dual rather than single identity facilitates the process of integration.

KEYWORDS: Identity; Eritrean; culture; immigrants; qualitative; integration

\section{Introduction}

Ethnic diversity in the UK has rapidly increased in the last decade with nearly fourteen per cent of the population now belonging to ethnic minority groups (Policy Exchange 2014). Over this period of time, Eritreans have made up the third largest group to cross the Mediterranean Sea in hope for a better life in the Western part of the world (Amnesty International 2016). Eritrea is an East African country located in the Horn of Africa and has a history of colonization and war. Migration initially increased after 1998 as the government imposed new policies designed to safeguard the fragile new nation and rebuild its economy and war-torn infrastructure (Giorgis 2014; The American Team for Displaced Eritreans 2014), yet it has now been 
recognized that the Eritrean population is amongst the most oppressed in the world (Kingsley 2015). Although there is currently no war in Eritrea, over five per cent of its population of 5.6 million have fled their country in the past year due to its government regime (Human Rights Watch 2015; BBC 2016a, 2016b). Some of the reasons behind many choosing to flee Eritrea involve the absence of freedom of expression, arbitrary arrests as well as a compulsory national service (Human Rights Watch 2015). This has caused a permanent sense of fear amongst many Eritrean civilians (UNHCR 2012) resulting in numerous individuals taking unbelievable risks to escape the Eritrean regime (Giorgis 2014). This paper explores in depth one of the many issues raised by this transition into a new country; namely identity.

Howard (2000) has defined identity as being the need to express who we are, which in turn is modified through an individual's social contexts and group memberships. Similarly, La Barbera (2015) recognized how the concept of identity has become increasingly central to social science. She highlighted how research has explored the meanings, conflicts and expectations relating to a diversity of settings, and how the expression of these representations constitute elements of identity. Ethnicity is core to the notion of identity, and there are several theories that have been used with this focus in mind. This paper will draw upon the social identity approach and the acculturation model.

Central to social identity approach (Tajfel and Turner 1979; Turner et al. 1987) is the differentiation between an in group and out group through the process of social categorization, with social identity being an individual's sense of who they are, based on these group memberships. From this perspective, it is argued that individuals selfcategorize themselves into groups that they identify with as a means to establish a social identity which in turn provides individuals with a sense of belonging. Accordingly, individuals are prone to express a subjectively favourable outlook of fellow ingroup members, which is usually motivated by a positive view of the self (Eckes, Trautner, and Behrendt 2005). Furthermore, Abrams and Hogg (1988) argue that positive differentiation enhances levels of self-esteem, as positive identities are established in which one feels content. Some research has supported this approach with a focus on ethnic minorities. For example, Townley et al. (2011) concluded that 
members of ethnic minority groups need to be exposed to a sense of support and understanding from their ingroup as well as outgroup in order to encourage integration. In terms of Eritreans, Iavasile (2012) found that many Eritreans choose to seek asylum in the UK due to the extensive community networks in British cities, which reflects their own sense of community within their more collectivistic culture (Triandis 1995). Iavasile (2012) also concluded that the UK offers greater opportunities for Eritreans to maintain the cultural and social roots especially in metropolitan cities such as London. Further, Chase (2013) suggested that many Eritreans view the UK as a place of security and hospitality, as many feel they have opportunities to connect with individuals in the same predicament as themselves. This suggests that members of the Eritrean diaspora may express high levels of group identification due to selfenhancement relating to their culture of origin alongside the culture of their host country. Nonetheless, Berry (1990) noted that an ideal multicultural society would enable individuals to implement an integrationist approach, which encourages the adoption and appreciation of multiple cultures. Initiatives as such may impact levels of integration amongst Eritreans in British societies which will presumably heighten and positively influence the identities of those in question. Furthermore, the dual identity model (Gaertner and Dovidio 2000) suggests that it is less threatening to people's social identity when they are able to keep both their original identity as well as a new, common identity.

An additional approach to understanding identity in the context of immigration is through the process of acculturation. Berry (1990) developed a model of acculturation and proposes that levels of acculturation arise as individuals maintain their cultural connections, yet have a desire for involvement and interaction with those from a host country by willingly adapting to their surroundings. This model also highlighted how this adaptation process includes aspects of economic, psychological and sociocultural modifications and concluded that positive cultural exchange is necessary to ensure that acculturation is achieved effectively. To support this model, Berry (2005) concluded that implementing acculturation strategies is effective in enabling members of ethnic minorities groups to combine their "home culture" with the culture of their new country of residence. Furthermore, he concluded that integration encourages 
intergroup relations, as it minimizes conflict amongst members of a society by initiating relations across cultures which in turn, encourages greater levels of acceptance amongst a wider society (Berry 2005). In support of this, Chen et al. (2013) concluded from their quantitative study, that although managing multiple cultural identities can present individuals with complex challenges and can be highly conflicting at times, a sense of acceptance and tolerance is vital, both for acculturation for the individual and successful globalization for the wider society.

In summary, the population of the UK has changed dramatically over the past decade. This is particularly pertinent given the current migrant crisis occurring across Europe and although the majority of these migrants are escaping from Syria, a significant minority are from Eritrea. This study therefore focused on the experiences of the Eritrean diaspora and will draw upon social identity and the Model of Acculturation to explore the impact of these experiences upon identity. In particular, this exploratory qualitative study aimed to gain an in depth insight into the expectations of new as well as settled Eritreans currently residing in the UK and the extent to which they felt that their experiences, whether positive or negative, had influenced their social identities.

\section{Method}

\section{Design}

A qualitative design was used involving semi-structured interviews to gain a rich understanding of the experiences of newly arrived and settled Eritrean immigrants currently residing in the UK.

\section{Ethical issues}

The study raises a number of ethical issues. First, some participants had recently fled their country and therefore were quite vulnerable. Second, some participants were still in the process of sorting out their paperwork to be able to stay in the UK and may have felt vulnerable about their residential status. Third, even those with established status may have felt vulnerable and reluctant to disclose too many personal details. As a result the interview focused solely on their experiences since living in the UK and 
addressed issues of integration and expectations. Further, the interviews were carried out in a familiar and safe environment, in their own language and by a researcher who originated from their own country. The study was given favourable ethical approval by the university's ethics committee.

\section{Participants}

The sample consisted of two groups of ten participants each selected by snowball sampling: (1) newly arrived Eritreans who had been in the UK for less than twelve months at the time of the interviews taking place; (2) settled Eritreans who had been in the UK for more than seven years. Participant demographic details are shown in Table 1. All participants have been given pseudonyms.

\section{Procedure}

Semi-structured interviews were conducted with participants in English or Arabic, lasting approximately forty-five to sixty minutes each. The newly arrived participants were recruited by the means of posters advertised in a local café in Birmingham popular to Eritreans, as well as by word of mouth from the personal contacts of the researcher. The settled participants were recruited via the personal contacts of the researcher in Birmingham. Both groups consisted of an almost equal number of male and female participants aged between twenty-four and sixty-two years old. The individuals were initially approached by telephone to make arrangements for a date and time to carry out the interview. Participants who spoke neither English nor Arabic were excluded from the study due to a language barrier. All participants received an information sheet and consent form prior to the study taking place, ensuring confidentiality and anonymity. The interviews with the newly arrived participants were carried out in the café in which the study was advertised, in a silent room which had been booked prior to the interviews taking place. The interviews with the settled participants were carried out in their homes all within the Birmingham area. 
Table 1. Participants demographics (newly arrived and settled).

\begin{tabular}{|l|c|c|c|c|}
\hline \multicolumn{1}{|c|}{ Name } & Gender & Age Group & Children & Time spent in the UK \\
\hline Omar $\left(\mathrm{N}^{*}\right)$ & Male & $20-30$ & Yes & 11 months \\
\hline Alia $\left(\mathrm{N}^{*}\right)$ & Female & $30-40$ & No & 9 months \\
\hline Daniel $\left(\mathrm{N}^{*}\right)$ & Male & $20-30$ & No & 9 months \\
\hline Khadeja $\left(\mathrm{N}^{*}\right)$ & Female & $20-30$ & Yes & 11 months \\
\hline Mariam $\left(\mathrm{N}^{*}\right)$ & Female & $30-40$ & Yes & 7 months \\
\hline Amin $\left(\mathrm{N}^{*}\right)$ & Male & $20-30$ & No & 10 months \\
\hline Yunees $\left(\mathrm{N}^{*}\right)$ & Male & $20-30$ & No & 12 months \\
\hline Najma $\left(\mathrm{N}^{*}\right)$ & Female & $40-50$ & Yes & 8 months \\
\hline Asmarina $\left(\mathrm{N}^{*}\right)$ & Female & $20-30$ & Yes & 11 months \\
\hline Eden $\left(\mathrm{N}^{*}\right)$ & Female & $20-30$ & No & 5 months \\
\hline Hasan $\left(\mathrm{S}^{*}\right)$ & Male & $50-60$ & Yes & 8 years \\
\hline Mustafa $\left(\mathrm{S}^{*}\right)$ & Male & $30-40$ & Yes & 9 years \\
\hline Amina $\left(\mathrm{S}^{*}\right)$ & Female & $60+$ & Yes & 15 years \\
\hline Winta $\left(\mathrm{S}^{*}\right)$ & Female & $40-50$ & Yes & 13 years \\
\hline Tesfay $\left(\mathrm{S}^{*}\right)$ & Male & $30-40$ & No & 8 years \\
\hline Sanait $\left(\mathrm{S}^{*}\right)$ & Female & $40-50$ & Yes & 7 years \\
\hline Kidane $\left(\mathrm{S}^{*}\right)$ & Male & $30-40$ & Yes & 20 years \\
\hline Amanuel $\left(\mathrm{S}^{*}\right)$ & Male & $30-40$ & No & 15 years \\
\hline Sofia $\left(\mathrm{S}^{*}\right)$ & Female & $20-30$ & Yes & 7 years \\
\hline Tekles $\left(\mathrm{S}^{*}\right)$ & Male & $40-50$ & Yes & 12 years \\
\hline & & & & \\
\hline
\end{tabular}

Note: $(\mathrm{N})=$ newly arrived; $(\mathrm{S})$ = settled.

Arabic were excluded from the study due to a language barrier. All participants received an information sheet and consent form prior to the study taking place, ensuring confidentiality and anonymity. The interviews with the newly arrived participants were carried out in the café in which the study was advertised, in a silent room which had been booked prior to the interviews taking place. The interviews with the settled participants were carried out in their homes all within the Birmingham area.

\section{Interview schedule}

The interview included the following questions with prompts where necessary:

(1) What expectations did you have of living in the UK? To what extent do you think these have been met? (2) Can you talk about any bad experiences you have had since moving to the UK? How have these influenced your perceptions of living here? (3) 
Can you talk about any good experiences you have had since moving to the UK? How have these influenced your perceptions of living here? (4) From your experience(s), to what extent do you feel that it is possible for a person to combine the Eritrean culture and the British culture? (5) How do you feel about the idea of integration? (6) Do you feel that Eritreans are integrating well in society? (7) Some people perceive themselves as British and others as Eritrean. How would you describe yourself? What does that mean to you? (8) Can you imagine a time where you can be Eritrean as well as British? If yes/no, why? (9) Is there anything that could help those from Eritrea become more integrated in the UK?

\section{The context to the study}

The study took place in Birmingham. It is therefore important to contextualize the data in terms of location, social class and language and religion. This information is from community leaders, the Eritrean Embassy and the Eritrean Ministry of Information.

\section{Location}

There are currently between 25 and 30,000 Eritreans living in the UK and the Eritrean Embassy estimates that approximately 5 and 7,000 of these reside in Birmingham. In fact, the UK has received at least 3,756 asylum applications from Eritrean nationals in the recent years (The Migration Observatory 2015) with Birmingham being one of the most popular destinations. Originally, Eritreans were one of the smaller ethnic minority groups and therefore the older generation in this particular community are quite close-knit. The overall community is organized by the means of two main subcommunities, consisting of Muslim and Christian Eritreans. Despite their religious beliefs, these communities regularly mix and significant annual events, such as the Eritrean Independence Day on the 24th May, tend to bring together the vast majority of Eritreans in Birmingham. Over recent years, community-led initiatives such as social events and fundraising campaigns have welcomed newly arrived Eritreans in Birmingham. Efforts to support the newly arrived individuals has meant that friendships have been created and support has been offered to newly arrived Eritreans who have been encouraged to develop according to their new surroundings by those 
more familiar with these. During some weekends and school holidays, activities and other social gatherings are often organized by active members of the Eritrean community as a means of empowering those new to the country by putting in place a support network. In addition, civic participation activities organized by The University of Birmingham, in partnership with Citizens UK, have been able to arrange events which have engaged some members of the Eritrean community in Birmingham (University of Birmingham 2016) and encourage individuals to speak of their personal journey.

\section{Social class}

The settled Eritreans in this study were working class although many of these have studied at Higher Education institutions but have not all been successful in securing their desired job role in the UK. Dependent on their residence status in the UK, newly arrived Eritreans are habitually provided with financial government support free education. Apart from this, existing members of the Eritrean community have previously been able to collectively offer some financial support as an act of charity, for newcomers who have had no recourse to public funds.

\section{Language and religion}

Eritrea comprises nine ethnic sub-groups with Tigrinya being the main language taught in schools (Eritrean Ministry of Information 2017). Despite this, most Eritreans are also taught to speak other languages such as Arabic as well as English (Tronvoll 2009). The researcher (SA) is not able to speak Tigrinya, but was still able to communicate with Tigrinya- speaking participants in one of the alternative languages who were therefore included in the study. The nine sub-groups, which are sometimes referred to as tribes, are generally spoken of in relation to lineage amongst Eritreans and are often not considered to be specific groups. Eritreans overall share common norms, values and beliefs across ethnic groups and religious differences as they have merged together and become one nation ever since gaining their independence as a country (Hirt 2014). Despite this, members of the Eritrean community do hold different political views and although many are against the current political agenda some have a more optimistic view about this. This may be due to a sense of appreciation about how Eritrea has gained independence from Ethiopia and, in spite 
of the current government regime, a belief in a better future (Hirt 2014). The participants interviewed were not questioned about their political views, but it can be assumed that those who have fled Eritrea are in opposition of the current regime.

\section{Data analysis}

The audio recordings were transcribed using an orthographic style and analysed following the five stages of Thematic Analysis (Braun and Clarke 2006): "data familiarisation", "initial coding generation", "searching for themes", "reviewing and refining themes" and "theme definition and labelling". This was an iterative process, with various themes, structures and labels considered before the final configuration was identified.

\section{Reflexivity}

The interviewer was a young woman who was brought up in Denmark, currently living in the UK and of Eritrean parentage who spoke fluent Arabic and English. As a third-generation Eritrean immigrant in the UK, she was engaged in the community and therefore able to have some insight to the levels of integration amongst immigrants and refugees from Eritrea. It was important for her to reflect upon how her background was influencing the interviews and analysis. These reflections were discussed between researchers, particularly when considering whether themes were grounded in the data. For example, as a young women she identified more strongly with the younger participants who were often those more recently arrived but as someone whose family had become integrated into the Eritrean community in Birmingham she also identified with those who had been here for longer as at times these were connected to her parents.

\section{Results}

Participants from both groups described some of the practical challenges they faced when relocating to the UK such as language barriers and concerns with regards to paper work. The analysis led to the identification of the following three themes, each with sub-themes: (1) Wanting freedom involving their expectations of the UK and a need to escape to safety and be free, (2) Integration and ways in which participants became part of the British community and (3) Personal development which involved 
growth and aspirations. Transcending these themes was the overarching theme of balance in which participants indicated a balance between their past and present lives and the two cultures. These themes will now be described and illustrated with exemplar quotes. Permeating all themes was the central role of identity which will be discussed in the discussion. The codes " $\mathrm{N}$ " and "S" are used to denote those who were newly arrived (<one year) and those who were settled (>seven years).

\section{Theme 1: wanting freedom}

The majority of participants described immigration from Eritrea to the UK as being due to a need for freedom. This was described in terms of (1) expectations, (2) safety and (3) gratitude based on their experiences of living in the UK.

\section{Expectations}

Prior to arriving in the UK, many of the participants expressed how they had expectations of what living in the UK would entail. This was illustrated by Najma (N) who had only been in the UK for eight months and described how she was "expecting to be settled [...] to be able to live a free life". For many, these expectations had been matched or at times surpassed by their experiences. Kidane (S) who had lived the UK for over twenty years said how his "expectations may have been exceeded". Likewise, as Yunees $(\mathrm{N})$ who had only been in the UK for twelve months said: "I have only had good experiences since arriving in the UK- it's been fantastic. Even better than I imagined it to be." On the other hand, Tesfay (S) expressed a different view and said that he: "didn't actually have any expectations [...] just camehere because I couldn't live in my country to continue my life as I wanted it to be".

\section{Safety}

Another notion which appeared to attract many participants to living in the UK was a feeling of safety. For example, Alia $(\mathrm{N})$ who is currently on the waiting list to be rehoused, said: "nothing is forceful here [in the UK]". Likewise, Khadeja (N), who arrived in the UK eleven months prior to the interview taking place, said that she felt: "very safe here. In Eritrea, people are scaredmany live in fear". This was similarly expressed by Amanuel (S) who had settled here just over fifteen years ago and said he: "just wanted to live somewhere, where I knew I would be safe". And Tekles (S) 
described how many Eritreans are simply: "searching for a better future in the Western part of the world. These people [Eritreans] came here for safety and not to create conflict". He argued that although some may perceive the arrival of newcomers as being problematic, he arrived with the sole purpose of desiring to feel safe whilst searching for a better quality of life.

\section{Gratitude}

Additionally, each participant interviewed expressed a sense of gratitude since arriving in the UK. This is illustrated by Daniel $(\mathrm{N})$ who had lived in the UK for just over nine months, who said he: "appreciate the opportunities I have been met with here, especially with regards to education and health". Similarly, Najma (N) said: "I have been treated very well since I arrived here."

The interviews indicated that the move to the UK and participants' experiences since being here were characterized by a desire for freedom illustrated through their emphasis on expectations, safety and gratitude. This finds reflection in much previous work on the experiences of those fleeing from danger and highlights the role that expectations play in experiences (Marino 2015), the role of safety as a key determinant of our sense of self (Maslow 1943), and how gratitude is commonly expressed by those who overcome hardship and face privileges they once lacked (Popovich 2014). It also reflects recent research specific to Eritreans which has reported how they often feel overwhelmed by opportunity and gratitude for this when arriving in countries such as the UK (Campbell and Afework 2015). Further, this parallels the information about the community in Birmingham and indicates that the attempts made to support and welcome new arrivals appear to be working.

\section{Theme 2: integration}

The interviews also showed a clear role for the importance of integration with participants emphasizing a need to become familiar and accepted in their new surroundings. In particular they discussed the importance of (1) ownership in terms of what they could do for themselves, (2) community in terms of what they could do for others and (3) the benefits of being integrated. 


\section{Ownership}

Many participants described how they needed to take control of integration and make it happen for themselves. Some participants described adopting particular coping strategies in order to integrate into the UK. As Omar $(\mathrm{N})$ described: "a person needs some time to familiarise themselves with their new surroundings". Mustafa (S) who arrived in the UK nearly ten years ago and was now a successful business owner described an alternative approach involving the strategy of lowering his expectations:

[...] expecting the absolutely unexpected. For me, this was a technique because it meant that I was prepared for the worst. As an outcome, everything was a lot easier than I had anticipated it to be. I think this is the best way of going about this kind of situation.

Some also described how integration took effort and could be a struggle. As Mariam (N) said: "you have to sometimes push yourself to become more engaging and active in society, for the sake of your own development". Further, some regarded integration more as a duty. As Hasan (S) said: "as immigrants must do our best because the very reason why we came here was to grow and make the best out of ourselves as individuals".

\section{Community}

Participants also emphasized the role of the Eritrean community and how it was the responsibility of more settled Eritreans to encourage the newcomers to settle in. In support of this is Winta (S) who arrived in the UK over thirteen years ago, said: "Collectively we need to make these new people feel welcomed and make them feel like they also belong here". Similarly, she also stated: "We need to implant positive values in the new-comers”. Furthermore, former diplomat Mustafa (S) said: “[...] we just need to motivate them and empower them to want to integrate and become a positive part of society".

Those Eritreans already settled in the UK therefore saw it as their responsibility as a community to help the process of integration. This was also reflected in the words of the newcomers who described how they needed the help and support of their community. As Alia (N) said of others: "they should lead the way for the many people who need guidance". Likewise, sixty-two-year old Amina (S) described how: "Those who have been here for a long time could act as great models for those who have just 
arrived here because this will give them hope" (Amina). Some also saw integration as central to who Eritreans are. As Amina (S) said that: “[...] generally speaking, as Eritreans, we integrate easily [...] we are people of several religions who live side by side in our country, in comparison to some of our neighbouring countries". Some also described how integration was not just the responsibility of the Eritrean community but also the wider society. As Yunees (N) stated: "when we are being accepted, we are willing to integrate more".

\section{Benefits}

Many also expressed the benefits of integration and saw it as central to the transitional process. For example, Sanait (S) spoke about her experience of living in the UK and said that: "integrating is important when adapting to a new place

[...] It's wonderful when you can combine cultures making it all equally important". Likewise, Daniel $(\mathrm{N})$ portrayed integration as a way of: "growing and becoming a person who will adapt various aspects of the British culture to my identity". The process of integration was not, however, straightforward and clear for everyone. For example, Tesfay (S) who arrived in Britain over eight years ago felt that as a community they were not integrated enough: "many of us spend a lot of time with our own affairs. I mean, on a whole we are integrating, but I do feel that more could be done". And taxi-driver Tekles (S) said: "I disagree with assimilation. I don't agree with being expected to change my way of life and conform to something out of my nature."

In sum, participants spoke clearly about the process of integration and its benefits and regarded it as a product both of their own actions and those of their community. In particular, whilst many described a number of coping strategies to help them integrate they also highlighted a willingness to support others which is line with the events and celebrations offered by the community and the determination of those more settled members to help newcomers fit in. This reflects previous research identifying the role of coping strategies when dealing with situations which are perceived as challenging (Prati and Pietrantoni 2009). It also supports evidence that individuals strive for acceptance when moving from one community to another (Fischer et al. 2004). Further, it also confirms the importance of social contexts for the 
development of inter group relations and the input of collective action for sustaining community (Townley et al. 2011) and illustrates that integration through individual and community responsibility can be a means of hope amongst members of minority ethnic groups (Benhabib 2002). Accordingly, the results indicate that even if individuals are keen to integrate the degree of this integration is reliant upon the new context they find themselves in the degree of support and openness they encounter. Not all participants were equally positive about integration and there were a minority of dissident voices in the sample. This may be due to the frustrations at taking employment below their level of education obtained in Eritrea. It may also illustrate that despite their best attempts at support and integration some individuals still fall through the net.

\section{Theme 3: personal development}

The final dominant theme reflected the desire for personal development as a key motivation for coming to the UK. This was illustrated in terms of (1) growth and (2) aspirations.

\section{Growth}

For many, personal development involved a sense of growth which was closely related to evolving on a deeper level. When asked about their experiences of living in the UK and the impact this had had on them, participants such as Omar $(\mathrm{N})$ said that: “Living here has influenced me in a way that has helped me and encouraged me for a desire to grow and develop as a person, that I had slightly given up on becoming at some point in my life." Although Omar arrived in the UK only eleven months prior to the interview his sense of self-assurance and will-power had quickly returned. Similarly, Amina (S) who had lived in the UK for over fifteen years, spoke about growth in terms of expanding and exploring:

In Eritrea, there was only one type of people [...] here, my mind was introduced to many different kinds of people and this pushed me to explore [...] Inspired me to stand out and educated people about myself and where I am from too.

Those who had been here for longer also described the opportunity for growth that the UK offered for their children. For example, Sofia $(S)$ who has been settled in the 
UK for several years now described how she was: "especially very grateful that my children have been provided with a good education system and they are doing very well academically".

\section{Aspiration}

The majority of the participants interviewed also spoke about having aspirations as key reasons for relocating to the UK. This was often expressed with regards to academic goals as illustrated by Winta (S) who said that: "[...] education is key. This is one of the main things that will help you develop and grow". Similarly, Amanuel (S) spoke about his positive experience since arriving in the UK and said that: "We have opportunities here to become educated at any age. The system here allows you to become more educated and this encourages integration." Further, Kidane (S) said: "I was able to get back into education and pursue my dream. I have now got a degree in Accounting and Finance." This perspective was not reflected in the accounts of all participants however, with a minority describing how the UK system prevented them from progressing. As Mustafa (S) said:

I have a degree in Economics, but when I came here this was not something I could make use of [...] Despite my qualifications and all my past experiences, I found it hard to find a suitable job in my level of expertise... often leads people to settle for jobs way below their standards.

Personal development was therefore a key factor in the decision to move to the UK and involved a desire for growth and aspirations particularly concerning education. This reflects the notion of evolvement as the prime motivator of globalization (Arnett 2002). It also illustrates the ways in which encounters with different social groups and aspirations can facilitate growth and promote integration (Schwartz et al. 2010; Tjosvold 2015).

\section{Overarching theme: balance}

On a whole, the participants described their transition to the UK as being due to a desire for freedom and safety, the process of integration which was a product of both individual and community action and personal development through growth and aspirations. Transcending these themes was the notionof balance reflecting an equilibrium between participants' cultural past and their present lives in the UK. For 
example, whilst they had become engaged in British life through its culture, education and employment they also sustained a sense of being Eritrean which is epitomized by Mustafa (S), who arrived in the UK nearly a decade ago:" [...] fairly straight-forward to be a product of more than one culture- more than two cultures even...comes down to you as a person and how willing you are to accept the beauty in our differences". This was illustrated through the sub-themes of (1) cultural heritage and (2) making a contribution.

\section{Cultural heritage}

Despite relocating to the UK many of the participants still described a sense of belonging to their ethnic roots in Eritrea. This resulted in a balance between a sense of pride for where they had come from whilst still integrating into the UK. At times this was associated with their age when they had arrived in the UK. As described by Eden (N): "I will always emphasize and have a strong connection with Eritrea, especially having arrived here at this age and having spent the majority of my life in Eritrea." For some, this attachment to their roots was also due to the people they had left behind and a sense of nostalgia and warmth towards their past. This was shown by Asmarina (N) who had arrived in the UK last year: "My life in Eritrea was also good, but in a different way to here. I miss my family and friends. I will never forget my roots...." For some, this was also due to their status and engagement in their home community. For example, Tesfay (S) spoke about his past in Eritrea as follows: "I was a Judge back home, I served my community...I feel that a large part of me is tied with my past in Eritrea and the many things I was involved with" (Tesfay)

For many this also reflected a determination to maintain their Eritrean beliefs. For example whilst Sanait $(S)$ said that she has: "[...] adapted well to the life here [the $\mathrm{UK}]$ ". She also commented: "But that's not to say that I haven't kept my Eritrean cultural norms and values." Likewise Sofia (S) said that: "[...] it's important to hold on to your personal norms, beliefs, and values- but that doesn't mean that you should completely disregard those of the country you are currently in". Further, this appreciation of their past was also embedded within a strong sense of identity. Amin $(\mathrm{N})$ is a prime example of this as he stated that: "As much as I would like to absorb 
knowledge about people and places I am not familiar with; I will make a point of also expressing my cultural identity in my encounters" (Amin)

\section{Making a contribution}

This sense of balance between the past and present was also reflected in the desire to use their Eritrean roots to make a contribution to British society. As stated by Kidane (S), who has spent most of his life in the UK:

we need to be proud of ourselves, our backgrounds, our history, in order to enrich our fellow members in society...this is what I am referring to when I say that in order to take, we should also give something of ourselves back.

Similarly, Sanait (S) described how: "I have been able to add from the British culture to my Eritrean identity...it has taught me to be very accepting of people around me." For many this ability to contribute to British society was seen as a characteristic specific to being from Eritrea. As Amanuel (S) stated:

Being accepting of other people is something we have in us already because back home our country consists of Muslims and Christians who all live side by side. We are all the same at the end of the day. We all have a love for each other despite our beliefs. Not many other countries can say this.

Participants therefore described a balance between their past in Eritrea with a strong sense of cultural heritage and their present lives in the UK. Further, participants saw this transition as an opportunity to make a contribution to the UK through their values and beliefs, particularly the Eritrean tradition of living side by side with different religions. This reflects previous research indicating that Eritreans maintain a strong sense of loyalty to their home country even when they have moved away and even if this movement was motivated by fear (Shearlaw 2015). It also illustrates how this sense of loyalty together with national pride enables Eritreans to have the confidence to believe that they have something positive to offer their new host country. Further, it highlights the strength of the Eritrean community in Birmingham and the ability of people with different languages, religions and ethnic sub-groups to generate a unifying sense of belonging.

\section{Discussion}

This study explored the experiences of newly arrived and settled Eritrean immigrants in the UK, focusing on how these may have influenced their social identities. The 
results illustrated how both groups had been motivated to come to the UK through a desire for freedom, and that in the main their expectations of safety and freedom had been met, for which they were grateful. They also described the benefits of integration which was considered a product of both individual and community action and appreciated the opportunities available to them in the UK for personal development. Although they had left their country and often their family and friends behind them, they felt integrated into their new surroundings which indicated a notion of balance, demonstrated by the co-existence of the past with their present and future lives. This balance was embedded with a strong sense of cultural heritage together with a desire to make a contribution to their new communities in the UK and reflects a sense of dual identity.

These findings can be understood within the context of the social identity approach (Tajfel and Turner 1979; Turner et al. 1987) and through the lens of acculturation (Berry 1990). The development of an identity is an iterative process between an individual's social and cultural contexts (Baumeister and Muraven 1996; Côté 1996). Further, acculturation is intertwined with identity as the reoccurring changes which arise during this process are viewed as having a direct impact on an individual (Schwartz et al. 2010). The results from the present study indicate how those Eritreans interviewed had moved away from their home country due to a desire for freedom and safety and had experienced a sense of personal development thereby resulting in a shift in their identity, to achieve a new positive social identity, in line with the social identity approach (Tajfel and Turner 1979; Turner et al. 1987). Furthermore, they had become integrated into UK society through both individual and social action and described the benefits of this process in line with the model of acculturation (Berry 1990).

This transition, however, does not appear to have created a new single identity either of being "not" Eritrean or of being "British" (assimilation) but for many participants this reflected a balance between their past and present and between both of the identities associated with these times (integration). This balance finds reflection in the notion of a "dual identity" whereby two identities become salient simultaneously, preventing their original identity as Eritreans being threatened by 
their new identity of being British (Berry and Sam 1997; Gaertner and Dovidio 2000) and is in line with research by Al-Ali, Black, and Koser (2001) specifically on the dual identities of Eritrean immigrants. This supports research by Barker (2015) who argued that despite ethnic minority groups placing emphasis on integrating within their host country, their "home-culture" still plays a large part in forming their core norms and values. It also reflects research exploring the transitions of Eritreans and the ability to integrate successfully whilst maintaining connectedness to Eritrea (Iavasile 2012). Further, it illustrates that whilst this strong attachment to their own country could be a hindrance to integration and subsequent acculturation, in the case of Eritreans it appears to facilitate this process through a desire to bring something of benefit to their new host country. Therefore, in line with Barker (2015) a positive balance between loyalties to two different countries and a resulting dual identity promotes rather than hinders acculturation which in turn leads to integration. There were some exceptions, however, to this emphasis on integration and balance which need to be highlighted. For example, one participant believed that their community was not integrated enough, one clearly did not want to integrate and some expressed frustration that they current level of employment did not meet their skills and education from their time before coming to the UK. It may therefore be the case that whilst many individuals are motivated to integrate and that this is facilitated by the context into which they move, those that feel frustrated by their current situation may experience less balance as their Eritrean identity still dominates over their British one.

To conclude, the past decade has seen a dramatic change in the population of the UK. This study explored the experiences of one of the largest minority groups, namely Eritreans, and indicated that many had been motivated to move to the UK through a desire for freedom and safety and had experienced a sense of personal development through growth and aspiration. The results also highlighted their desire for integration which was considered a product of both individual and community action. Further, the interviews indicated that, for many, their transition to the UK was reflected in an overarching notion of balance between their past and present lives resulting in a dual identity as they established a new equilibrium between a strong sense of cultural heritage together with a desire to make a contribution to their new 
host country. In line with social identity theory, many Eritreans interviewed showed a shift in their identity as they became embedded in their new social groups. However, rather than developing a new single identity, most participants accounts illustrated a dual identity, which rather than being a hindrance to integration was, in contrast, a facilitator as their strong sense of being Eritrean, and their loyalty and pride in their past enabled them to feel that they had more to offer to their host country in their futures. Therefore, it would seem that for Eritreans, a dual identity encourages acculturation which in turn promotes integration.

\section{Disclosure statement}

No potential conflict of interest was reported by the authors.

\section{References}

Abrams, D., and M. A. Hogg. 1988. "Comments on the Motivational Status of SelfEsteem in Social Identity and Intergroup Discrimination." European Journal of Social Psychology 18: 317-334. doi:10.1002/ ejsp.2420180403.

Al-Ali, N., R. Black, and K. Koser. 2001. "Refugees and Transnationalism: The Experience of Bosnians and Eritreans in Europe." Journal of Ethnic and Migration studies 27: 615-634.

Amnesty International. 2016. Eritrea 2015/2016 (2016, March, 11). https:/ / www. amnesty.org/en/countries/africa/eritrea/report-eritrea/.

Arnett, J. J. 2002. “The Psychology of Globalization.” American Psychologist 57: 774. doi:10.1037/0003-066X.57.10.774.

Barker, G. G. 2015. "Choosing the Best of Both Worlds: The Acculturation Process Revisited." International Journal of Intercultural Relations 45: 56-69.

Baumeister, R. F., and M. Muraven. 1996. "Identity as Adaptation to Social, Cultural, and Historical Context." Journal of Adolescence 19: 405-416.

doi:10.1006/jado.1996.0039.

BBC. 2016a. "Eritrea Country Profile" (2016, February, 14).

http:/ / www.bbc.co.uk/news/ world-africa-13349078.

BBC. 2016b. "Migrant Crisis: Migration to Europe Explained in Seven Charts" (2016, March, 14). http:/ / www.bbc.co.uk/news/world-europe-34131911.

Benhabib, S. 2002. The Claims of Culture: Equality and Diversity in the Global Era. Princeton: Princeton University Press.

Berry, J. W. 1990. “Acculturation and Adaptation: A General Framework." In Mental health of Immigrants and Refugees, edited by W. H. Holtzman, and T. H.

Bornemann, 90-102. Austin, TX: Hogg Foundation for Mental Health. Berry, J. W. 2005. "Acculturation: Living Successfully in Two Cultures." International Journal of Intercultural Relations 29: 697-712. doi:10.1016/j.ijintrel.2005.07.013.

Berry, J. W., and D. L. Sam. 1997. “Acculturation and Adaptation.” Handbook of Cross-Cultural Psychology, 3: 291-326. doi:10.1016/j. ijintrel.2005.07.013. 
Braun, V., and V. Clarke. 2006. "Using Thematic Analysis in Psychology." Qualitative Research in Psychology 3: 77-101. doi:10.1191/1478088706qp063oa. Campbell, J. R., and S. Afework. 2015. "Ethiopian and Eritrean Immigrants in Britain." African Diaspora, 8: 98-119.

Chase, E. 2013. "Security and Subjective Wellbeing: The Experiences of Unaccompanied Young People Seeking Asylum in the UK." Sociology of Health and Illness 35: 858-872.

Chen, S. X., V. Benet-Martínez, W. C. Wu, B. C. Lam, and M. H. Bond. 2013. “The Role of Dialectical Self and Bicultural Identity Integration in Psychological Adjustment."Journal of Personality 81: 61-75.

Côté, J. E. 1996. “Sociological Perspectives on Identity Formation: The CultureIdentity Link and Identity Capital." Journal of Adolescence 19: 417-428. doi:10.1006/jado.1996.0040.

Eckes, T., H. M. Trautner, and R. Behrendt. 2005. “Gender Subgroups and Intergroup Perception: Adolescents' Views of Own-Gender and Other-Gender Groups." The Journal of Social Psychology 145: 85-112.

Eritrean Ministry of Information. 2017. “Eritrea's 9 Ethnic Groups” (2017, February, 20). http:// www.shabait.com/about-eritrea/erina/16508-eritreas-9-ethnic-groups. Fischer, A. H., A. S. R. Manstead, C, Evers, M. Timmers, and G. H. Valk. 2004. "Motives and Norms Underlying Emotion Regulation." In The regulation of emotion, edited by P. Philippot, and R. S. Feldman, 187-212. Mahwah, NJ: Erlbaum. Gaertner, S. L., and J. F. Dovidio. 2000. Reducing Intergroup Bias: The Common Ingroup Identity Model. New York: Psychology Press.

Giorgis, A. W. 2014. Eritrea at a Crossroads: a Narrative of Triumph, Betrayal and Hope. Strategic Book. doi:10.1017/S0022278X1500066X.

Hirt, N. 2014. “The Eritrean Diaspora and Its Impacts on Regime Stability: Responses to UN Sanctions. African Affairs" (2017, February, 20).

https:/ / afraf.oxfordjournals.org/content/early/2014/11/20/afraf.adu061.full. Howard, J. A. 2000. “Social Psychology of Identities." Annual review of Sociology 26: 367-393. doi:10.1146/annurev.soc.26.1.367.

Human Rights Watch. 2015. World Report 2015: Eritrea (2016, February, 16). https:/ / www.hrw.org/world-report/2015/country-chapters/eritrea.

Iavasile, M. 2012. "Exploring the Eritrean Diaspora in Italy and in the United Kingdom." Doctoral diss., Universita Ca'Foscari Venezia.

Kingsley, P. 2015. "It's Not at Aar, but up to 3\% of Its People Have Fled. What Is Going on in Eritrea?" (2016, March, 5).

https:/ / www.theguardian.com/world/2015/jul/22/ eritrea-migrants-child-soldierfled-what-is-going.

La Barbera, M. 2015. “Identity and Migration: An Introduction.” In Identity and Migration in Europe: Multidisciplinary Perspectives, 1-13. Springer International. doi:10.1007/978-3-319-10127-9.

Marino, S. 2015. "Surviving Mechanisms of Power in Immigration Strategies:

Embracing Otherness and Pluralisms." Journal of International Political Theory 11: 167-183. doi:10.1177/1755088214550115.

Maslow, A. H. 1943. "A Theory of Human Motivation." Psychological Review 50: 370-396. doi:10.1037/h0054346. 
Policy Exchange. 2014. “A Portrait of Modern Britain” (2016, March, 13).

http:/ / www.policyexchange.org.uk/images/publications/a\%20portrait $\% 20$ of $\% 20$ mode\%20rn\%20britain.pdf.

Popovich, P. A. 2014. Cultivating Gratitude after Loss: A Cross-Cultural, MixedMethods Research Approach. Doctoral diss., Sofia University.

Prati, G., and L. Pietrantoni. 2009. "Optimism, Social Support, and Coping Strategies as Factors Contributing to Posttraumatic Growth: A Meta-analysis." Journal of Loss and Trauma, 14: 364-388. doi:10.1080/15325020902724271.

Schwartz, S. J., J. B. Unger, B. L. Zamboanga, and J. Szapocznik. 2010. “Rethinking the Concept of Acculturation: Implications for Theory and Research." American Psychologist 65: 237. doi:10.1037/a0019330.

Shearlaw, M. 2015. "Outside Eritrea Looking in: A Diaspora that Stands Divided". https:/ / www.theguardian.com/world/2015/aug/20/eritrea-diaspora-dividedyour-stories.

Tajfel, H., and J. C. Turner. 1979. “An Integrative Theory of Intergroup Conflict.” The Social Psychology of Intergroup Relations 33: 33-74.

The American Team for Displaced Eritreans. 2014. "Eritrea and Its Struggles". http://eritreanrefugees.org/.

The Migration Observatory. 2015. "Migration to the UK: Asylum”. http:/ / www. migrationobservatory.ox.ac.uk/resources/briefings/migration-to-the-uk-asylum/. Tjosvold, D. 2015. Building the Team Organization: How to Open Minds, Resolve Conflict, and Ensure Cooperation. Springer. doi:10.1057/9781137479938.

Townley, G., B. Kloos, E. P. Green, and M. M. Franco. 2011. “Reconcilable Differences? Human Diversity, Cultural Relativity, and Sense of Community." American Journal of Community Psychology 47: 69-85. doi:10.1007/s10464-0109379-9.

Triandis, H. C. 1995. Individualism and Collectivism. Boulder: Westview Press. Tronvoll, K. 2009. The Lasting Struggle for Freedom in Eritrea: Human Rights and Political Development, 1991-2009. Oslo: Center for Peace and Human Rights. Turner, J. C., M. A. Hogg, P. J. Oakes, S. D. Reicher, and M. S. Wetherell. 1987. Rediscovering the Social Group: A Self-categorization Theory. New York: Blackwell. UNHCR. 2012. Fear of Compulsory Recruitment Drives Eritrean Teen to Flee Home (2016, February, 27). http://www.unhcr.org/news/stories/2012/3/4f6777426/fearcompulsoryrecruitment- drives-eritrean-teen-flee-home.html.

University of Birmingham. 2016. Community Engagement (2017, February, 19). http://www.birmingham.ac.uk/university/colleges/socsci/partnerships/citizensuk/collaboration/aditi-session.aspx. 